\title{
The Use of Hydroxyurea in the Treatment of COVID-19
}

\author{
Melissa Robin Bowman Foster ${ }^{1 *}$, Ali Atef Hijazi², Rebecca Opoku², Priya Varghese², \\ Chun $\mathrm{Li}^{2}$ \\ 1 Winston-Salem State University, Winston-Salem, NC, USA \\ 2 Independent
}

\section{ABSTRACT}

Introduction: The rapid worldwide spread of COVID-19 motivated medical professionals to pursue and authenticate appropriate remedies and treatment protocols. This article aims to analyze the potential benefits of one treatment protocol developed by a group of care providers caring for severe COVID-19 patients. Methods: The clinical findings of COVID-19 patients who were transferred to a specialized care hospital after unsuccessful treatment in previous institutions, were analyzed. The specialized care hospital used a treatment protocol including hydroxyurea, a medication commonly used for sickle cell treatment, to improve respiratory distress in the COVID-19 patients. None of the COVID-19 patients included in the analyzed data were diagnosed with sickle cell, and none had previously taken hydroxyurea for any other conditions. Results: In all presented cases, patients reverted to their baseline respiratory health after treatment with the hydroxyurea protocol. There was no significant difference in the correlation between COVID-19 and hydroxyurea. However, deaths were extremely low for those taking hydroxyurea. Conclusions: Fatality numbers were extremely low for those taking hydroxyurea; death could be attributed to other underlying issues.

Keywords: COVID-19, treatment, hydroxyurea, critical respiratory care

Received: 30 December 2020 / Accepted: 15 June 2021

\section{INTRODUCTION}

Since first being identified in December 2019 in China, the coronavirus disease 2019 (COVID-19) caused by severe acute respiratory syndrome coronavirus 2 (SARS-CoV-2) has quickly lead to a worldwide pandemic. As deaths continue to rise worldwide, medical professionals across the world are eager to find the best treatment to ensure favorable prognoses for infected patients [1].

Currently there is no standard worldwide protocol for treating Covid-19 patients. Many treatment options have been used including chloroquine or hydroxychloroquine, convalescent plasma, and interleukin-6 inhibitors. Currently, the National Institutes of Health (NIH) recommends against the use of chloroquine and hydroxychloroquine as well as anti-IL-6 receptor monoclonal antibodies for the treatment of COVID-19. The $\mathrm{NIH}$ will not recommend for or against the use of convalescent plasma for COVID-19 treatment because of insufficient data but states it should currently not be considered the standard of care for treatment of COVID-19 patients [2]. The NIH does currently recommend the use of dexamethasone in patients who require supplemental oxygen, both with and without mechanical ventilation but should be closely monitored for side effects such as hyperglycemia, psychiatric effects, secondary infections, and avascular necrosis [3].

In the most severe cases, patients will require intubation because of hypoxemia. During intubation, medical professionals continue to treat patients with a combination of different drugs based on clinical findings but no drug has proven to be effective enough to become part of a standard protocol [4].

Hydroxyurea, also known as hydroxycarbamide, is an oral medication commonly used to manage sickle cell disease. Additionally, it has also been used to treat certain cancers, most commonly leukaemia and cervical cancer. In sickle cell disease, hydroxyurea increases fetal haemoglobin concentration in patients by increasing nitric oxide levels. The increase in nitric oxide leads to activation of guanylyl cyclase, therefore, increasing 
cyclic guanosine monophosphate (cyclic GMP). This rise in cyclic GMP activates gamma-globin gene expression and gamma chain synthesis, which results in the production of fetal haemoglobin [5]. The resulting increase in fetal haemoglobin led to providers adding hydroxyurea to the COVID-19 treatment protocol, further explained in the Clinical Observations section.

This article presents clinical observations made after treating patients with a protocol including hydroxyurea.

\section{Clinical ObSERVATIONS}

In April 2020, a specialty hospital in North Carolina, United States of America, began a treatment protocol for newly admitted severe COVID-19 patients. The hospital is licensed as a long-term acute care facility focusing on critical illness recovery. Patients referred to this hospital are typically those who have survived an illness or injury but continue to show signs of weakness and have a need for considerable medical care.

The clinical findings summarized here are focused on severe COVID-19 patients. All patients were transferred to the specialty hospital after showing no signs of improvement at the initial admitting hospitals. Patients were sent to this specialty hospital because one of the primary focuses of the hospital is weaning medically complex patients from mechanical ventilation. All of these patients had been referred to palliative treatment with a prognosis of little to no chance of improvement from the referring hospitals. However, the patients and patient advocates wanted to continue looking for facilities that would offer curative treatment with the hopes of improvement. That led to their care being transferred to the specialized care hospital. None of the patients observed had been diagnosed with sickle cell disease or had any other prior treatment involving hydroxyurea.

The patients observed were admitted between May 2020 and September 2020. Patients were previously treated with varying combinations of antibiotics, convalescent plasma, remdesivir, dexamethasone, steroids, and tocilizumab. Treatment procedures included percutaneous endoscopic gastrostomies (PEGs) and tracheotomies. Breathing assistance included fraction inspired oxygen $\left(\mathrm{FiO}_{2}\right)$, positive end-expiratory pressure (PEEP), non-aerosol generating (NAG) automatic tube compensation (ATC), and high flow oxygen.

Within 24 hours of admission, all patients began the specialty hospital's COVID-19 treatment protocol.
1. hydroxyurea, $500 \mathrm{mg}$ PO BID X 10 days

2. solumedrol, $60 \mathrm{mg}$ IV Q 6 hours, continued until discharge but slowly tapered to oral administration

3. folic acid, $2 \mathrm{mg}$ IV daily, continued until discharge

4. anticoagulation medicine - heparin, enoxaparin sodium or apixaban, continued until discharge

5. fish oil - Omega 3, 300 milligrams per gram, $6 \mathrm{~g}$ daily, continued until discharge

6. modafinil, $100 \mathrm{mg}$ daily, continued until discharge

7. amantadine, $100 \mathrm{mg}$ daily, continued until discharge

8. famotidine, $40 \mathrm{mg}$ IV BID, continued until discharge

9. IV antibiotics as needed based on culture results

Nine patients were observed, both male and female, ranging in age from 51-76. All patients were diagnosed with COVID-19 and had moderate to severe hypoxemia.. Eight of the nine patients were intubated prior to admission to the specialty hospital; one of the eight intubated patients had the tube removed prior to being transferred to the specialty hospital. All seven of the observed intubated patients had their tubes after starting the hospital's COVID-19 treatment protocol. The average number of days on the COVID-19 treatment protocol before tube removal was 14 days.

All nine patients improved sufficiently to be discharged to a rehabilitation facility. Upon discharge, all patients had returned to their respiratory health status prior to their COVID-19 diagnosis. The average number of days on the COVID-19 treatment protocol until discharge was 19 days.

Table 1 provides a summary of all presented case studies of patients receiving the specialty hospital's COVID-19 treatment protocol.

\section{-HYPOTHESIS}

The primary focus of this protocol is the use of hydroxyurea. Thus far in the COVID-19 pandemic, hydroxyurea has not been a medication commonly used in treatment protocols [5]. It has been observed that COVID-19 patients suffer from hypoxia, and the severe cases suffer to the extent of requiring mechanical ventilation. However, it has also been observed that chest imaging on COVID-19 patients does not always correlate with the low oxygen values, especially in the early stages of infec- 
Table 1. Summary of presented case studies of patients receiving specialty hospital's COVID-19 treatment protocol

\begin{tabular}{|c|c|c|c|c|c|}
\hline $\begin{array}{l}\text { Case } \\
\text { number }\end{array}$ & Prior treatment & $\begin{array}{l}\text { Duration of } \\
\text { illness prior } \\
\text { to beginning } \\
\text { COVID-19 } \\
\text { treatment } \\
\text { protocol }\end{array}$ & $\begin{array}{l}\text { Number of } \\
\text { days on } \\
\text { treatment } \\
\text { protocol before } \\
\text { extubation }\end{array}$ & $\begin{array}{l}\text { Number of days } \\
\text { on treatment } \\
\text { protocol before } \\
\text { discharge to } \\
\text { rehabilitation } \\
\text { center }\end{array}$ & $\begin{array}{l}\text { Respiratory } \\
\text { support at } \\
\text { discharge }\end{array}$ \\
\hline 1 & $\begin{array}{l}\text { convalascent plasma, tracheoto- } \\
\text { my, PEG, FIO2 60-100\%, PEEP }\end{array}$ & 35 days & 12 days & 24 days & room air \\
\hline 2 & $\begin{array}{c}\text { convalascent plasma, tocili- } \\
\text { zumab }\end{array}$ & 30 days & 7 days & 10 days & room air \\
\hline 3 & $\begin{array}{l}\text { convalescent plasma, remdesivir, } \\
\text { dexamethasone }\end{array}$ & 34 days & 5 days & 10 days & room air \\
\hline 4 & $\begin{array}{l}\text { IV heparin, remdesivir, dexa- } \\
\text { methasone, high flow oxygen } \\
\text { 15L (NOTE: NO INTUBATION } \\
\text { REQUIRED) }\end{array}$ & 23 days & $\begin{array}{l}\mathrm{N} / \mathrm{A} \text { - patient } \\
\text { did not require } \\
\text { intubation }\end{array}$ & 13 days & $\begin{array}{c}3 \mathrm{~L} \text { O2 per minute, } \\
\text { bilevel positive } \\
\text { airway pressure at } \\
\text { night }\end{array}$ \\
\hline 5 & $\begin{array}{c}\text { IV antibiotics, dexamethasone, } \\
\text { tracheostomy, PEG }\end{array}$ & 21 days & 16 days & 29 days & $\begin{array}{l}1 \text { L O2 by nasal } \\
\text { cannula PRN } \\
\text { nightly }\end{array}$ \\
\hline 6 & $\begin{array}{l}\text { convalescent plasma, remdesivir, } \\
\text { tocilizumab, FiO2 30\%, PEEP }\end{array}$ & 37 days & 19 days & 28 days & room air \\
\hline 7 & $\begin{array}{l}\text { remdesivir, IV steroids, oxymizer } \\
6 \mathrm{~L} \text { per minute }\end{array}$ & 96 days & $\begin{array}{l}\text { N/A- patient ex- } \\
\text { tubated prior to } \\
\text { starting protocol }\end{array}$ & 9 days & $\begin{array}{l}2 \mathrm{~L} \text { by nasal can- } \\
\text { nula }\end{array}$ \\
\hline 8 & $\begin{array}{l}\text { dexamethasone, remdesivir, cef- } \\
\text { triaxone sodium, azithromycin, } \\
\text { convalescent plasma }\end{array}$ & 35 days & 28 days & 33 days & $\begin{array}{l}2 \mathrm{~L} \text { by nasal can- } \\
\text { nula PRN }\end{array}$ \\
\hline 9 & remdesivir, actemra, solumedrol & 63 days & 11 days & 15 days & $\begin{array}{l}2 \mathrm{~L} \text { by nasal can- } \\
\text { nula PRN }\end{array}$ \\
\hline
\end{tabular}

tion [6]. Knowing this, the suggestion was made that the low oxygen levels were resulting from abnormalities at the microscopic level in the capillaries during gas exchange. From this thought process, medical providers began to focus on medications that would assist at the capillary gas exchange level, therefore leading to the addition of hydroxyurea to the treatment protocol for severe, intubated COVID-19 patients.

As mentioned, hydroxyurea increases the amount of fetal hemoglobin ( $\mathrm{Hb} \mathrm{F}$ ) in red blood cells (RBCs). This leads to increased hemoglobin oxygen affinity and potentially assisting with gas exchange in the body and helping maintain adequate oxygen levels. In addition, in sickle cell patients, hydroxyurea stabilizes RBCs and reduces hemolysis in sickle cell disease (SCD), which in turn reduces free hemoglobin in the capillary space that will worsen endothelial dysfunction. Hydroxyurea also increases nitric oxide levels which could improve blood flow [5].

Although the treatment protocol only requires a 10 day, minimal dose of hydroxyurea, it is essential to mention the potential side effects of the drug. Longterm use of hydroxyurea has been associated with skin cancer, painful non-ulcerative erythema, and aphthous ulcers. Additionally, continued use of hydroxyurea can lead to myelosuppression which can result in leukopenia, thrombocytopenia, and anemia. Therefore, all patients on the protocol were monitored continually with complete blood count (CBC) panels, skin checks, and other routine measures for monitoring hospital inpatient status [5].

As COVID-19 patients present with low arterial oxygen saturation, providers began to consider the effects increasing fetal hemoglobin would have on the partial pressure of oxygen (PaO2). One study by Dhont et al. (2020) [7] suggests COVID-19 patients should not be treated in the same way as critically ill patients in respiratory failure because their intense hypoxemia is not accompanied by major signs of respiratory distress, forcing providers to think of other more atypical ideologies of the hypoxemia. The study suggests low arterial oxygen saturation as a possible compromising factor. 
This advocates having increased levels of fetal hemoglobin would increase $\mathrm{PaO} 2$ and ultimately aid in oxygen delivery. Since the induction of fetal hemoglobin in red blood cells by hydroxyurea is not uniform [8], oxygen delivery to tissues may not be compromised.

All patients presented with severe COVID-19 infection with most requiring mechanical ventilation due to severe hypoxia. After treatment with the protocol including hydroxyurea, all case study patients improved, mechanical ventilation was removed, and patients were discharged to a rehabilitation facility which was the hospital's goal for patients presenting with severe illness.

Since the original nine patients included in these clinical summaries were treated, an additional 46 patients have been treated using the same protocol bringing the total number of patients treated with the hydroxyurea protocol to 55 . Again, all 55 patients were suffering from severe COVID-19 and had failed to respond to other treatments. Out of the 55 patients seen to date as of April 2021, 47 have made a full recovery and reverted back to pre-COVID respiratory status and eight failed to recover.

\section{DATA ANALYSIS}

To further analyze the impact of hydroxyurea use on clinical outcomes in patients with COVID-19, we searched for data sets including diagnosed COVID-19 cases and patients taking hydroxyurea. The Medical College of Wisconsin has created a registry to capture worldwide confirmed COVID-19 patients living with sickle cell disease [9]. This data set is constantly being updated. The analyses provided below are based off the data update provided October 2, 2020.

The total number of reported COVID-19 cases diagnosed in patients with sickle cell disease worldwide is 359 . Of the reported study population, 212 were 19 or older and the remaining 147 were 18 or below making them pediatric cases (Figure 1). Of the patients reported, 164 were male, 190 were female, and 5 did not answer and/or identify with either gender (Figure 2). Of the 359 total reported, 192 were taking hydroxyurea prior to their COVID-19 diagnosis (53.8 $\%$ ) (Figure 3). Of the 192 patients taking hydroxyurea, 86 were male and 106 were female (Figure 4). Of the 192 patients taking hydroxyurea, 81 were 18 years old or younger and 111 were age 19 years or older (Figure 5). Of the 359 patients reported as of August 28th, 2020 , there have been 16 fatalities. Of those 16 fatali-

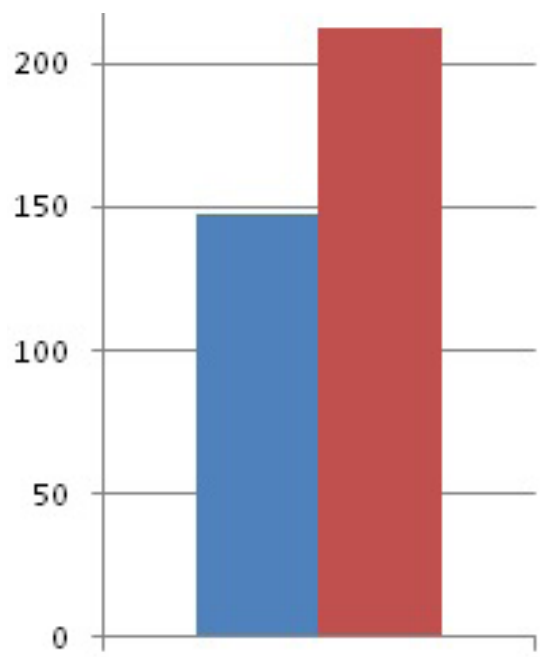

age $\leq 18$ years

age $\geq 19$ years

Fig. 1. Study population information

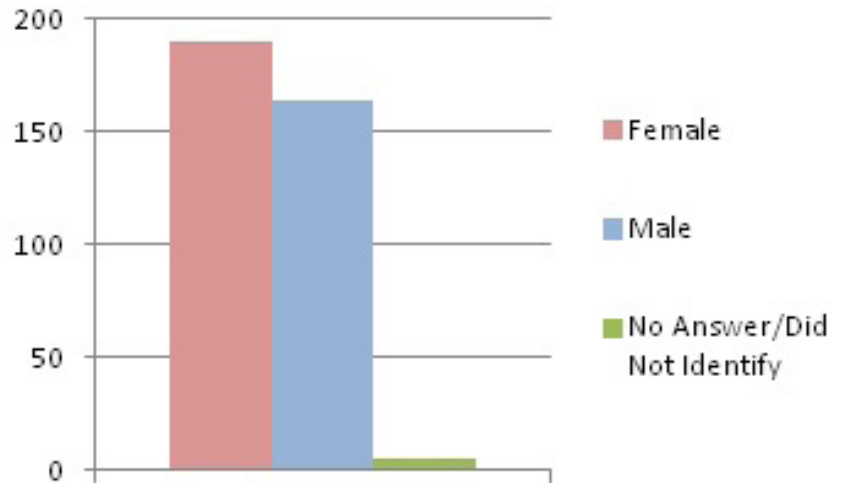

Fig. 2. Study population gender information

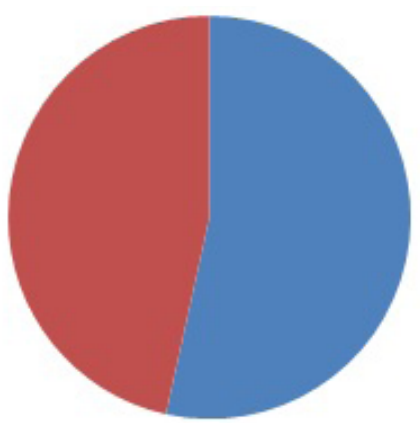

Taking hydroxyurea prior to VOCID-19 diagnosis

Not taking hydroxyureaprior to COVID-19 diagnosis

\section{Fig. 3. Study population taking hydroxyurea prior to} COVID-19 diagnosis

ties, 7 were taking hydroxyurea and 9 were not. When compared, the mortality rate of total patients taking hydroxyurea (192) is 3.65\% compared to a mortality rate of $5.39 \%$ for total patients not taking hydroxyurea (167) (Figures 6 \& 7) .

\section{DONCLUSIONS/RECOMMENDATIONS}

Other researchers have observed that sickle cell patients seem to have a better prognosis than most pa- 


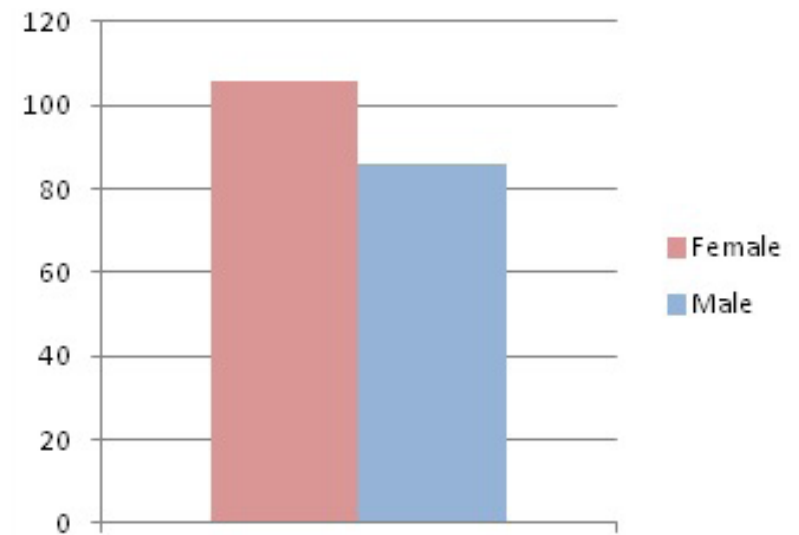

Fig. 4. Gender information for patients taking hydroxyurea

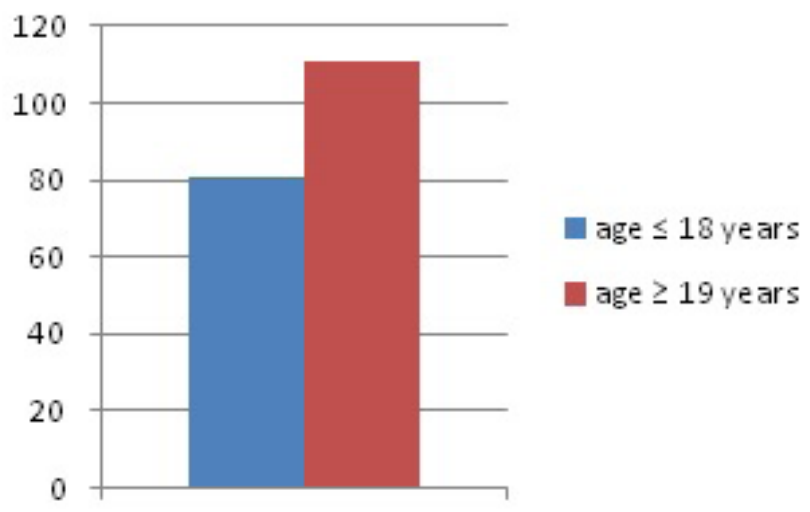

Fig. 5. Age information for patients taking hydroxyurea

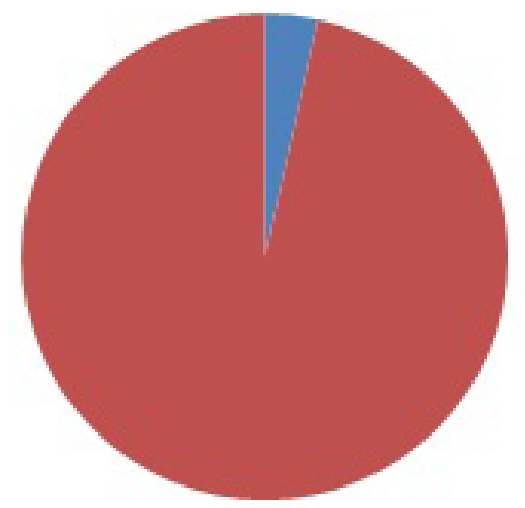

fatal outcome

non fatal outcome

Fig. 6. Mortality of patients taking hydroxyurea

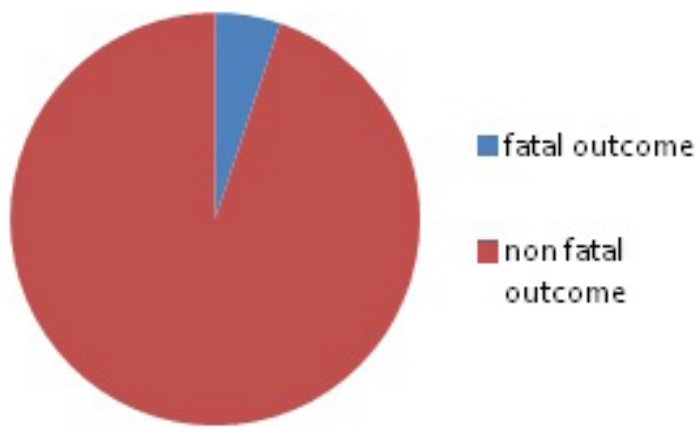

Fig. 7. Mortality of patients not taking hydroxyurea tients when diagnosed with COVID-19. For example, in a recent study by Ramachandran et al. [10], in New York City, nine sickle cell patients were hospitalized with a diagnosis of COVID-19. Of those nine, six were taking hydroxyurea prior to their COVID-19 diagnosis. The study concluded that, although sickle cell patients should be high risk due to compromised immune systems from their underlying disease, they were "somehow protected from severe symptoms and complications of COVID-19 infection.”

After reviewing the presented case studies, analyzing the data from the Medical College of Wisconsin's registry, and evaluating recent findings from other studies, it is suggested that hydroxyurea could be a potential treatment to greatly improve the prognosis of patients with severe symptoms of COVID-19. It is also possible hydroxyurea could be beneficial with any stage of COVID-19 infection involving the heart and lungs due to its ability to improve oxygenation; therefore, it could prevent deterioration that may lead to mechanical ventilation. Hydroxyurea is a drug with few side effects and is extremely cost efficient and readily available. With close monitoring, this drug could safely be used to treat severe COVID-19 cases, which would allow more data collection and case studies to validate or negate the potential use of this drug for COVID-19 treatment purposes. A larger scale, prospective study is warranted to determine the clinical significance of these recommendations.

Additionally, the large data set used only provided outcomes on sickle cell disease patients. The use of hydroxyurea on these patients could be affected by factors associated with sickle cell disease such as organ damage from chronic disease, potential effects from long term use of hydroxyurea, and race/ethnicity. Again, more data collection on non-sickle cell patients being treated with hydroxyurea would provide more insight on the use of this medication outside of sickle cell treatment.

Suppose research finds hydroxyurea to be useful in the treatment of COVID-19 patients suffering from severe respiratory distress after undergoing prolonged mechanical ventilation. In that case, further research could focus on the use of hydroxyurea for use in any patients experiencing non-resolving respiratory failure. Hydroxyurea is affordable, readily available, and has minimal side effects which would make it efficient for these types of trials. 


\section{口CONFLICTS OF INTERESTS}

None to declare.

\section{ACKNOWLEDGEMENTS}

We would like to thank Dr. Daniel B. Kim-Shapiro and Dr. Ziad Salem for helpful discussions and critical readings of this manuscript; Dr. Anupama Matcha, Dr. Saadat Khan, and Dr. Stephanie Brown for their work in the treatment of COVID-19 patients; and Dennis W. Bowman for invaluable connections, may his memory live forever.

\section{REFERENCES}

1. Wiersinga WJ, Rhodes A, Cheng AC, et al. Pathophysiology, Transmission, Diagnosis, and Treatment of Coronavirus Disease 2019 (COVID-19): A Review. JAMA. 2020; 324(8):782793. doi:10.1001/jama.2020.12839

2. National Institutes of Health. Covid-19 Treatment Guidelines. https://www.covid19treatmentguidelines.nih.gov/whatsnew/

3. Halpin DMG, Singh D, Hadfield RM. Inhaled corticosteroids and COVID-19: a systematic review and clinical perspective. European Respiratory Journal. 2020; 55(5): 2001009. https:// doi.org/10.1183/13993003.01009-2020

4. Tobin MJ. Basing respiratory management of COVID-19 on physiological principles. Am J Respir Crit Care Med. 2020;201(11):1319-1320. doi:10.1164/rccm.202004-1076ED

5. Nevitt SJ, Jones AP, Howard J. Hydroxyurea (hydroxycarbamide) for sickle cell disease. Cochrane Database of Systematic Review. 2017; 4: CD002202. doi: 10.1002/14651858. CD002202.pun2.

6. Shi $H$, Han $X$, Jiang $N$, et al. Radiological findings from 81 patients with COVID-19 pneumonia in Wuhan, China: a descriptive study. Lancet Infectious Disease. 2020;20(4):425434. doi:10.1016/S1473-3099(20)30086-4

7. Dhont S, Derom E, Van Braeckel E, et al. The pathophysiology of 'happy' hypoxemia in COVID-19. Respiratory Research. 2020; 21( 198). https://doi.org/10.1186/s12931-020-01462-

8. Khandros E, Huang P, Peslak SA, et al. Understanding heterogeneity of fetal hemoglobin induction through comparative analysis of $\mathrm{F}$ and $\mathrm{A}$ erythroblasts. Blood. 2020;135(22):1957-1968. doi:10.1182/blood.2020005058

9. Panepinto JA, Brandow AM, Singh A. Secure-SCD Registry. Medical College of Wisconsin. (October 2020) https:// covidsicklecell.org/.

10. Ramachandran P, Perisetti A, Kathirvelu B, et al. Low morbidity and mortality with COVID-19 in sickle cell disease: A single center experience. eJHaem. 2020;1-7. https://doi. org/10.1002/jha2.87 